\title{
PEAK LEK
}

ATTENDANCE FOR

GREATER SAGE-GROUSE

WITHIN THE NORTHERN

\section{BIGHORN BASIN,}

\section{WYOMING}

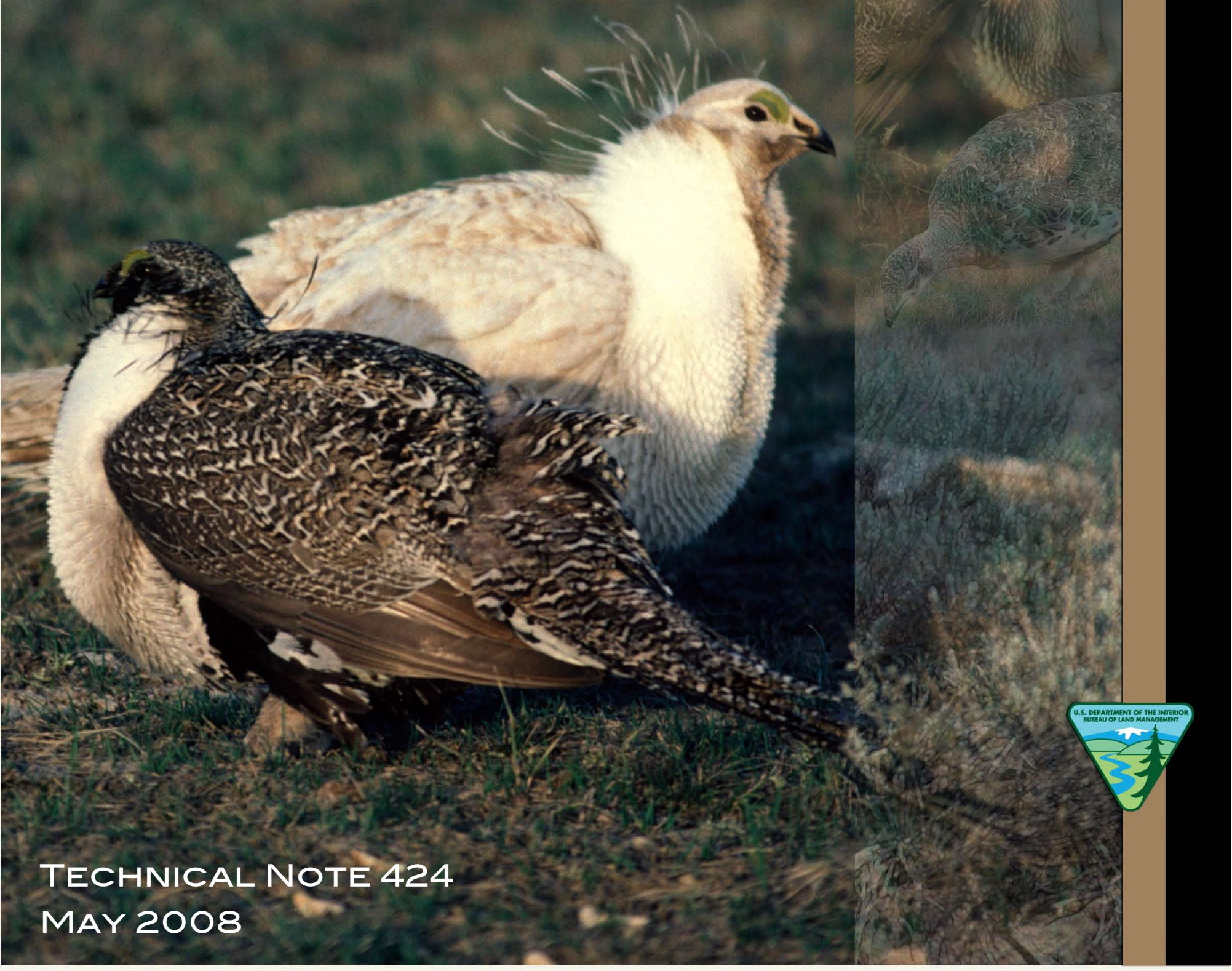




\section{SUGgESTED CITATION:}

Harrell, D. 2008. Peak lek attendance for greater sage-grouse within the northern Bighorn Basin, Wyoming. Technical Note 424. U.S. Department of the Interior. Bureau of Land Management, Cody Field Office, Wyoming. 12 pp. www.blm.gov/nstc/library/techno2.htm.

\section{Production services provided by:}

Bureau of Land Management

National Operations Center

Information and Publishing Services Section

P.O. Box 25047

Denver, CO 80225

\section{Available online at:}

www.blm.gov/nstcllibrary/techno2.htm 


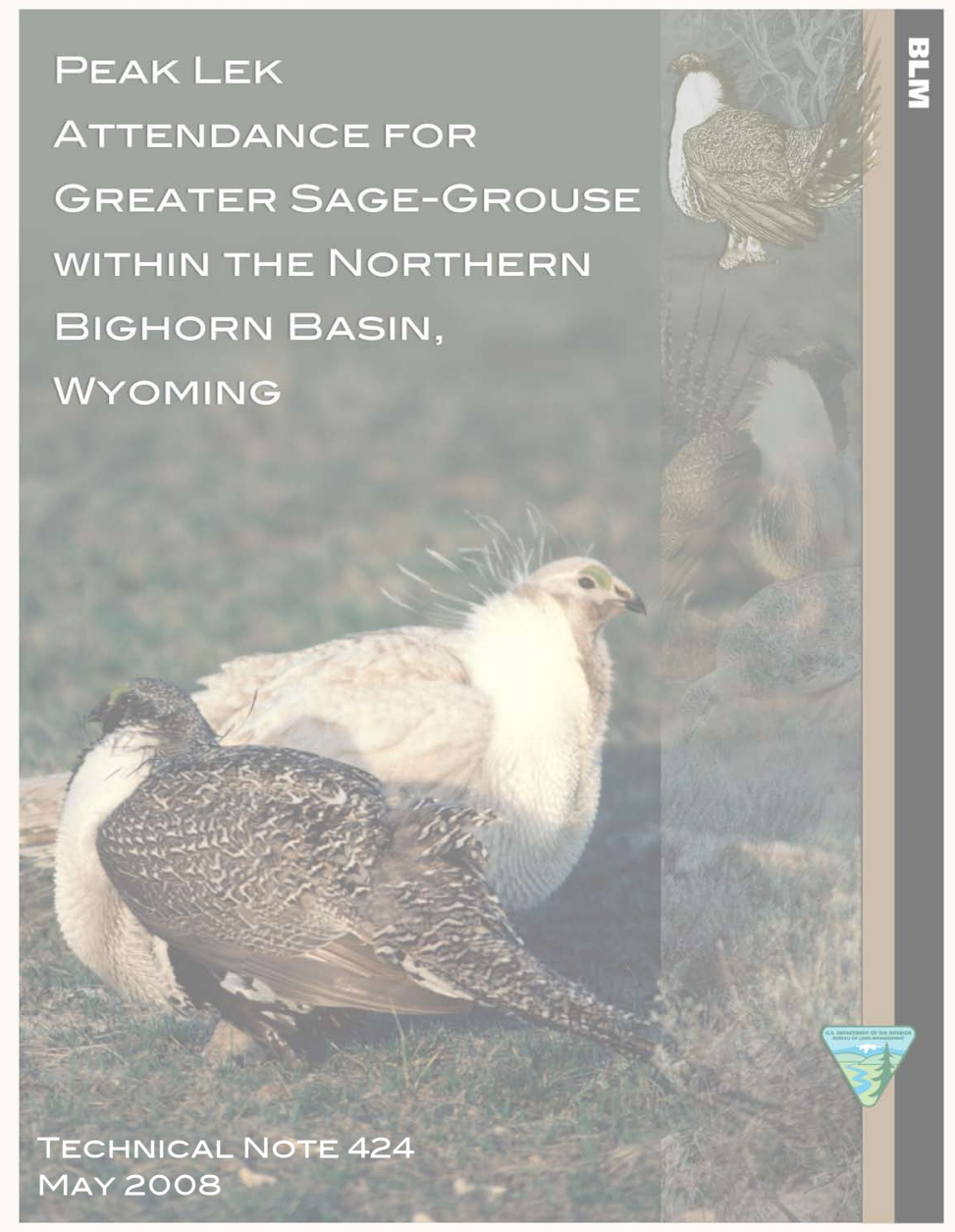

Peak Lek Attendance for Greater Sage-Grouse

within the Northern Bighorn Basin, Wyoming

Technical Note 424

By:

Destin Harrell

Wildlife Biologist

Bureau of Land Management

Cody Field Office, WY 


\section{ACKNOWLEDGMENTS}

I would like to thank the Wyoming Game and Fish Department for providing access to lek data and facilitating survey efforts. I am grateful to Lisa Marks and Brian Latta, who provided many edits and contributions, Eve Warren, who offered early advice, and Linda Hill and Janine Koselak from the National Operations Center, who were helpful in refining this document. I would also like to thank the staff of the Bureau of Land Management, Cody Field Office, for supporting this analysis and all who reviewed this study and made it better. I am also appreciative of pictorial and review contributions by Dave Goswick.

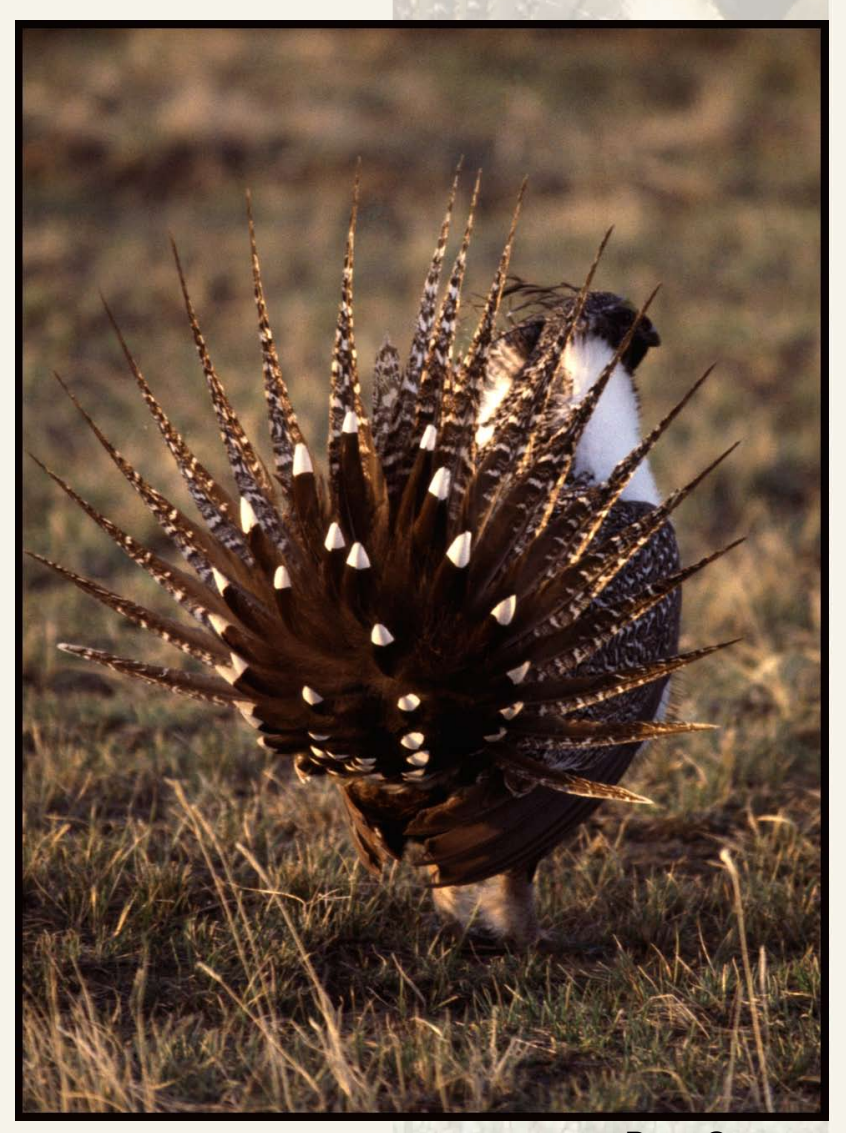

DAVE GOSWICK 


\section{CONTENTS}

ABSTRACT

INTRODUCTION

METHODS

RESULTS

DISCUSSION

LITERATURE CITED
VII

1

3

5

7

11

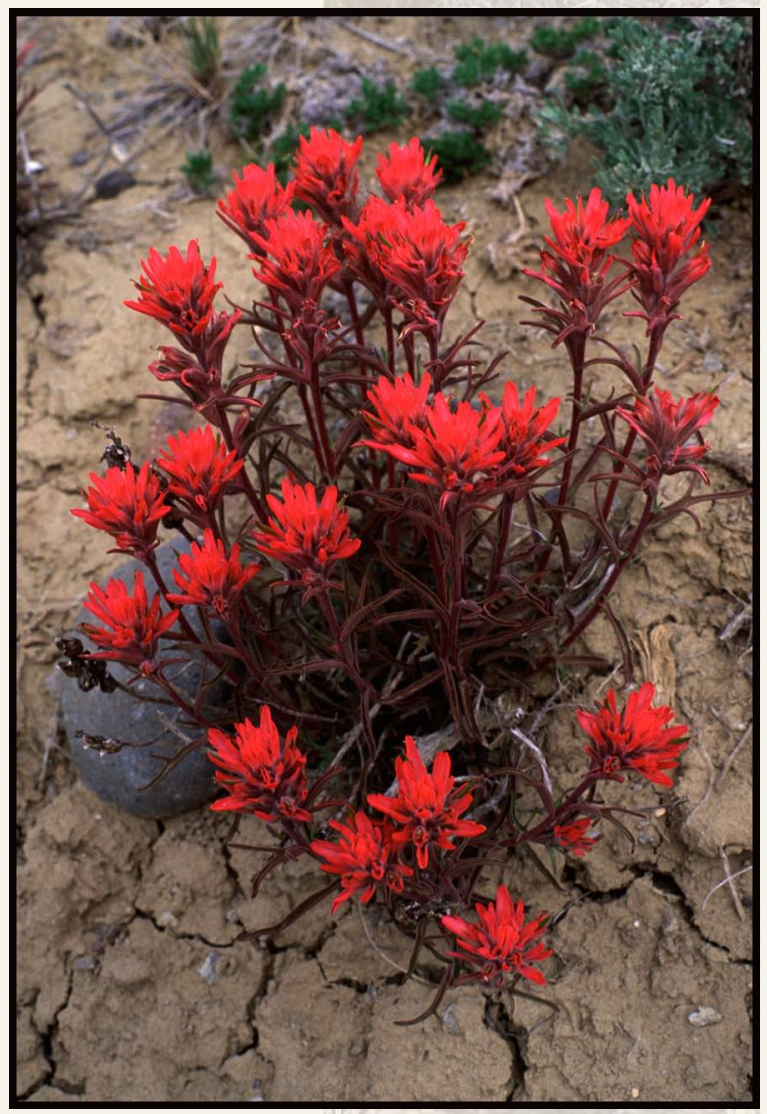

DAVE Goswick 


\section{ABSTRACT}

Lek attendance surveys were analyzed to gain a better understanding of the life history of greater sage-grouse (Centrocercus urophasianus) on lands administered by the Bureau of Land Management's Cody Field Office (northern Bighorn Basin, WY). The frequency distributions of sampled high observations were analyzed relative to the range of days in the lek attendance season from 1958 through 2005. The mean frequency distributions for male and female high observations were considered lek attendance peaks. The female peak had a mean high observation frequency around April 9 and the male peak had a mean high observation frequency around April 13. These peaks were significantly separated $(\mathrm{P}<0.0001)$. Computation of a 95 percent confidence interval suggests the male peak may be between 2.83 and 5.07 days later than the female peak. These local results are relatively early in the lek attendance period when compared to other observations in Wyoming and suggest that after the female peak attendance, a peak in male attendance closely follows. Local identification of peak attendance periods may help improve local nesting, fledging, and brood-rearing period inference. Existing life history information, combined with local peak female attendance data, suggests that peak nest initiation for the Bighorn Basin may begin April 12, peak incubation may begin April 21, and peak fledging/broodrearing activity may begin May 16. Improved inference may also lead to improved decisions regarding habitat management and conservation.

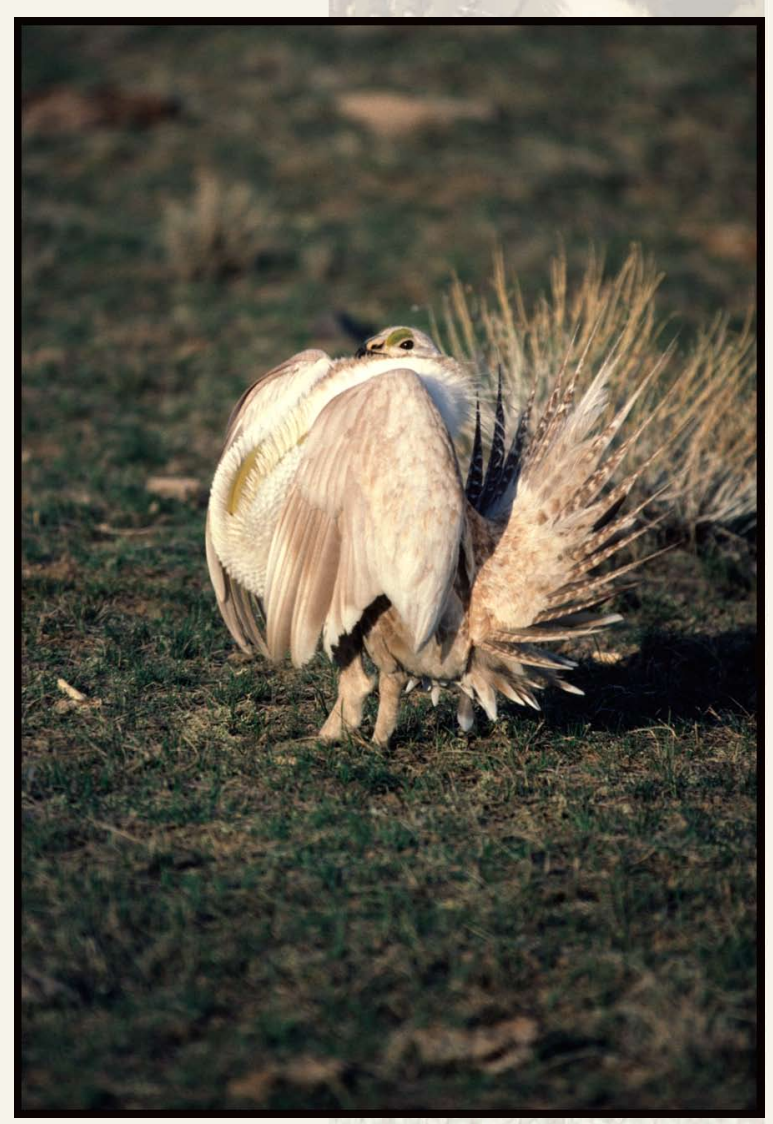

DAVE GOSWICK 


\section{INTRODUCTION}

The greater sage-grouse (Centrocercus urophasianus), hereafter referred to generally as sage-grouse, is adapted to vegetation communities dominated by woody sagebrush (Artemisia spp.). Sage-grouse populations and occupied habitat have been declining from the species' former range and numbers (Connelly and Braun 1997; Schroeder et al. 2004; Stiver et al. 2006). Differences in local and regional abiotic variables may influence when sagegrouse mate, nest, fledge, and move to winter habitat (Patterson 1952; Schroeder 1997).

Mating occurs each spring on traditional display areas called leks, where males attract females through mating displays exhibiting sexually dimorphic plumage (Young 1994; Connelly et al. 2003). This gathering provides an opportunity to count individuals and to monitor trends in lek attendance. Average or high male observations have been used as an indicator for population trends (Connelly et al. 2004; Walsh et al. 2004). The frequency distribution of these male and female high observations may also be useful when attempting to estimate peak lek attendance periods.

Generally female sage-grouse start to attend leks around early to late March; peak hen attendance may be as early as the middle of March and vary throughout the sage-grouse's range (Connelly et al. 2004). Soon after peak hen attendance occurs, their numbers may drop relatively quickly until only a small number of hens attend a lek each day, then a gradual increase in subadult males tends to appear (Connelly et al. 2004). The male peak attendance period has been reported to be approximately 3-5 weeks later than the female peak (Eng 1963; Jenni and Hartzler 1978; Emmons and Braun 1984; Connelly et al. 2004).

Prior to this study, analyses estimating the male or female peak sage-grouse lek attendance periods were absent in the Bighorn Basin, WY. Past studies in other regions have reported male and female peak lek attendance based on results from radio collared sagegrouse or short-term observations of a relatively small representative lek sample. Where baseline data have not been collected, the female lek attendance peak is the closest approximation of when females on average begin their reproductive timeline (Patterson 1952). If local female peak lek attendance was better known, life history information could be used to produce a timeline extrapolation of local nesting, fledging, and brood-rearing periods. An estimate of this timeline may provide decisionmakers the opportunity to avoid disturbing these sensitive life history periods by minimizing sources of disturbance, stress, and mortality.

The most relevant sage-grouse life history study for the Bighorn Basin was conducted by Patterson (1952) in southern Wyoming. On leks ranging between 1,951 and 2,438 meters (6,400 and 8,000 feet) above sea level, Patterson (1952) found that male attendance was at its highest in mid-April, peaking the third week of April. There was not much evidence for female peak attendance; however, there were substantial observations of other life history elements related to fledglings. Nesting activity commenced on or around 
April 20 and terminated by July 1 (Patterson 1952). Females retired to nesting areas and commenced egg-laying within a few days after mating, requiring an interval of approximately 35-40 days between breeding and hatching (Patterson 1952). According to Patterson (1952), hens began to lay eggs a few days after mating; 9 days were observed for completing an average clutch of 7.5 eggs (each egg laid approximately every 1.3 days), and a 25 - to 27-day incubation period was common, with peak hatching occurring the last week of May. Patterson's life history study offers an opportunity to initiate extrapolation of nesting and brood-rearing periods where this information has not been studied.

Normally, lek monitoring is conducted in each of three periods: late March or early April (i.e., March 20-April 7), mid-April (i.e., April 10-20), and late April (i.e., April 22-30) (Connelly et al. 2003). Monitoring may coincide with both peak female attendance (early counts) and maximum male attendance (middle or late counts) (Connelly et al. 2003). Since sage-grouse attendance varies among years and monitoring results vary with survey effort, Wyoming attempted to standardize search methodology by conducting lek monitoring according to the "Sage-Grouse Lek Survey and Search Methodology" developed by the Wyoming Game and Fish Department's Sage-Grouse Working Group in March 1998 (Easterly 2000). By 1999, lek monitoring

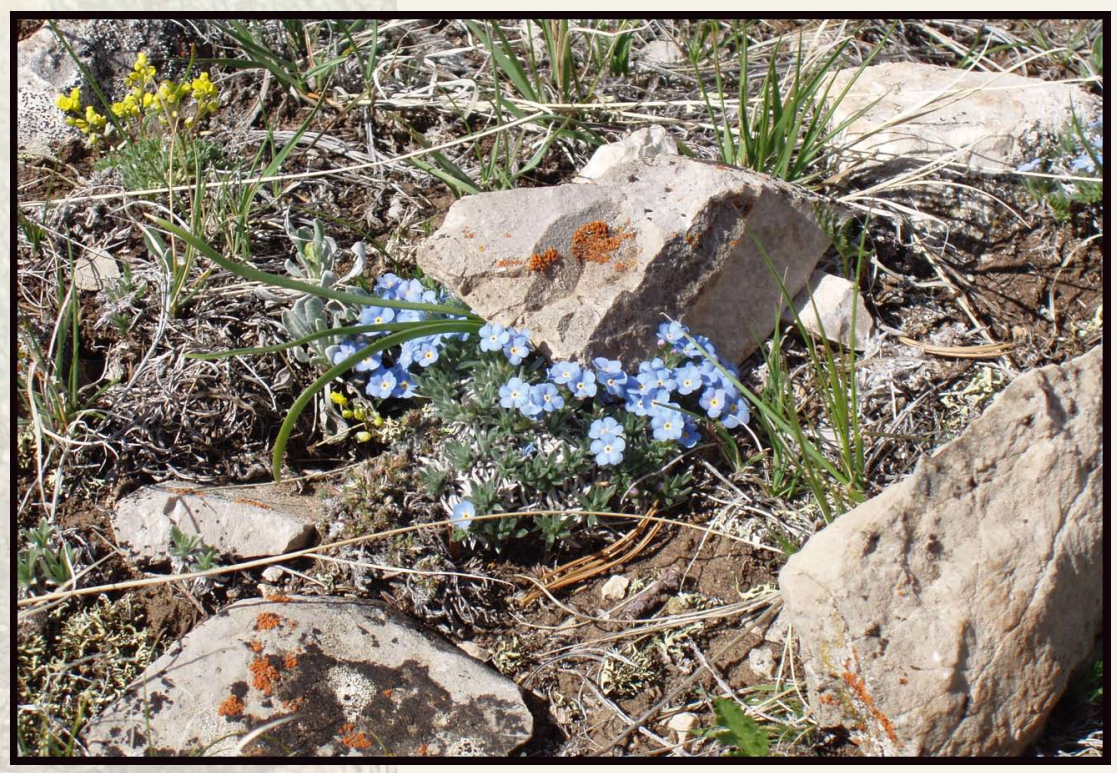

data in the Bighorn Basin were collected using this methodology (Christiansen 2005).

In recent years, the Wyoming Game and Fish Department has produced an annual sage-grouse lek monitoring report analyzing trends in these average male and female lek attendance data and using these trends to indicate sage-grouse population changes for the northern Bighorn Basin. These reports have shown slight declines in average male high counts (Easterly 2000; Christiansen 2005). Declines in abundance and distribution may be a result of habitat degradation and its negative effects on nesting success and recruitment (Holloran et al. 2005). Currently lek counts provide the best index of breeding population levels and make long-term data sets available for trend analysis (Emmons and Braun 1984; Braun and Beck 1996; Connelly and Braun 1997; Braun and Johnson 1999; Connelly et al. 2003; Stiver et al. 2006). However, short-term lek monitoring data may only reflect gross population changes and may provide misleading results (Connelly et al. 2003). Long-term trends in lek attendance data may be better indicators of relative sage-grouse population status, as population size fluctuates and confounds trend analyses in shorter time intervals (Walsh et al. 2004).

In the northern Bighorn Basin, where leks are generally lower in elevation, ranging between 1,300 and 1,700 meters (4,265 and 5,577 feet) above sea level, sage-grouse attendance and nesting periods may be influenced by different elevation and climate combinations (Patterson 1952). Life history demographics observed by Patterson (1952) suggest female peak attendance may be in early April. Since survival and reproduction is affected by disturbance to this reproduction timeline, which begins during the female peak lek attendance period, high male and female lek observation frequency distribution data from 1958 through 2005 were analyzed to determine when the male and female peak lek attendance occurs. 


\section{METHODS}

Source data ranging from 1958 through 2005 came from the Wyoming Game and Fish Department's sage-grouse lek attendance database for leks in the northern Bighorn Basin and north of the Greybull River to the Montana State line, which is the boundary for lands administered by the Bureau of Land Management's Cody Field Office (figure 1). Data from 1958 through 1998 were not subject to the systematic data collection standards found in the "Sage-Grouse Lek Survey and Search Methodology" developed by the Wyoming Game and Fish Department's
Sage-Grouse Working Group in March 1998 (Easterly 2000; Connelly et al. 2003).

Beginning in 1999 these data standards were implemented more consistently, with monitoring conducted in early March and extending into early May. Optimally, three lek visits (which involved recording the number of male and female sage-grouse observed, separated by $7-10$ days) were made for "count" leks and as time allowed, many additional leks were also monitored during each annual lek attendance season (Easterly 2000; Christiansen 2005).

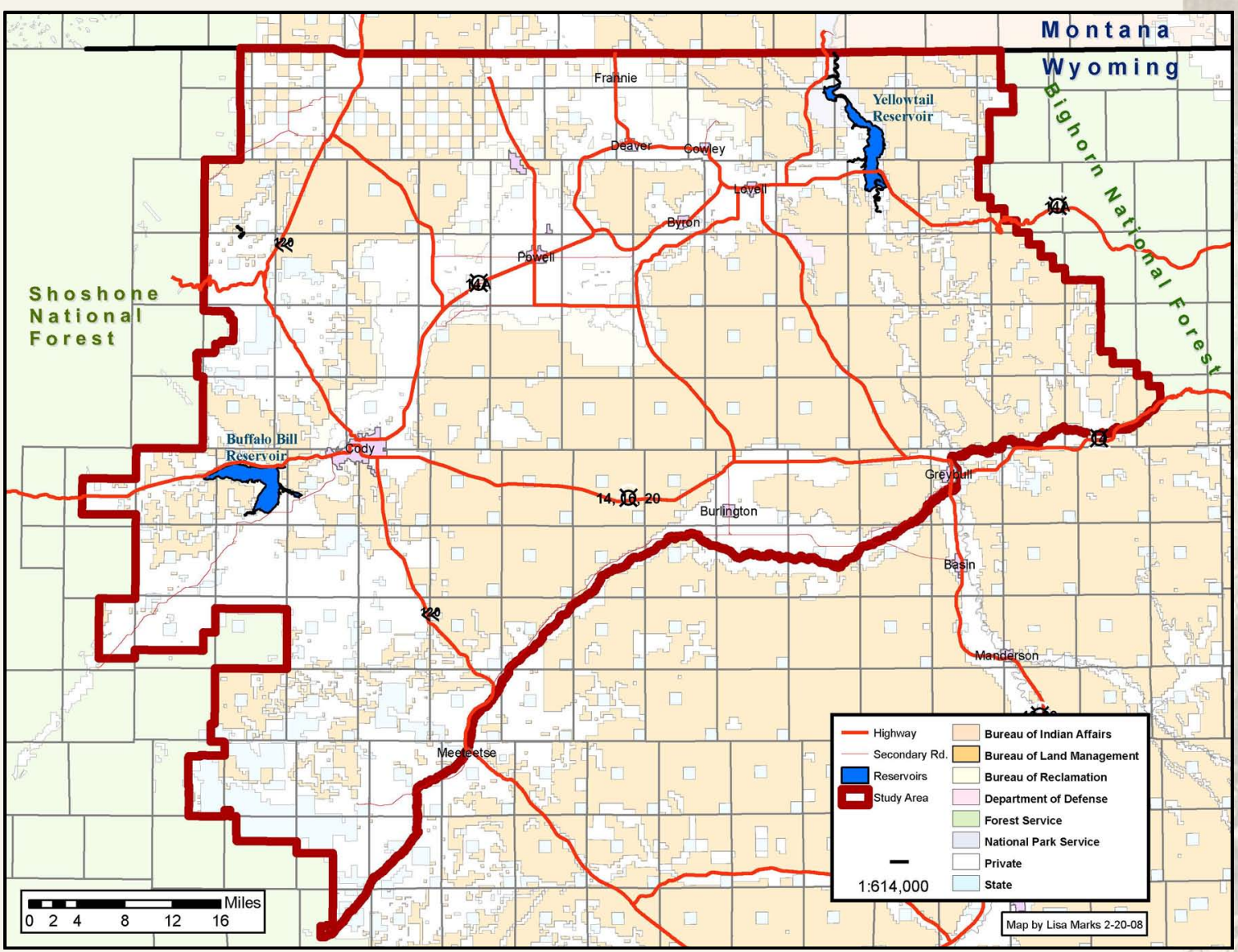

Figure 1. MAP OF THE SAge-grouse LeK StUdy AREA. 


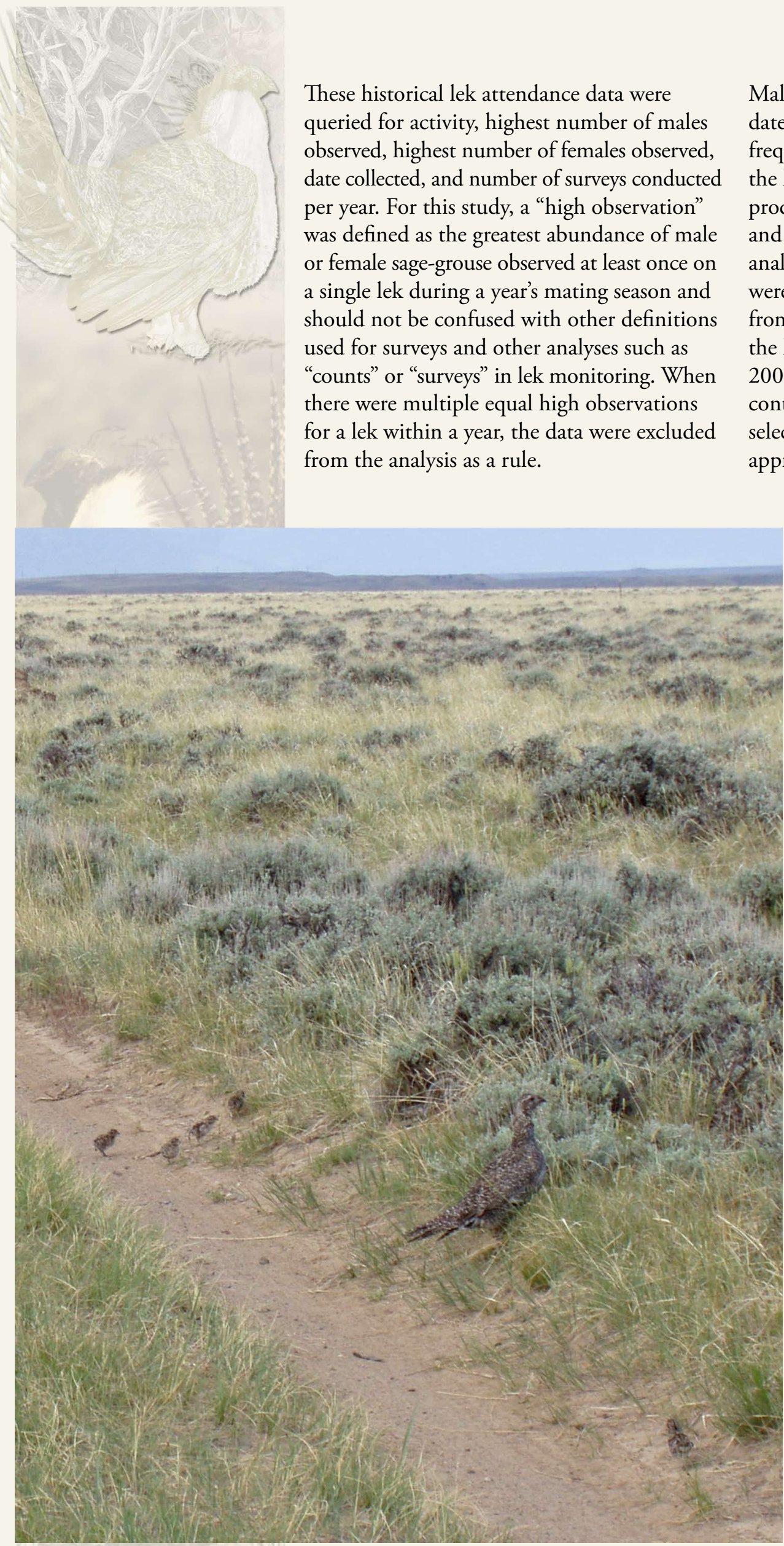

Male and female high observations and the date observed were queried and binned as frequencies (date of high observations through the lek attendance period). Histograms were produced for each data set showing the male and female frequency distribution. Statistical analyses within the frequency distribution were truncated or limited to observations from March 20 through April 30 (normally the lek monitoring period) (Connelly et al. 2003). This truncation was an attempt to help control for the biases of potential sampling selectivity. The frequency distributions were approximately normal, and a two-tailed $\mathrm{t}$-test assuming unequal variances was used to compare the means of these two frequency distributions. The null hypothesis $(\mathrm{H} 1=\mathrm{H} 2)$ for significance was set at $\alpha=0.05$ and a 95 percent confidence interval was calculated. Statistical analyses were conducted using Microsoft Office Excel 2003 and VassarStats: Web Site for Statistical Computation (Lowry 2007). 


\section{RESULTS}

The sampling period ranged from 1958 through 2005 (48 years), during which males were observed at 101 leks and females were observed at 95 leks. There were 2,565 total sage-grouse lek observations; 727 total high male observations and 492 total female high observations. From March 20 through April 30 , there were 636 high observations for males and 466 high observations for females. All male high observations ranged from March 1 through May 26 and all female high observations ranged from March 9 through May 25. The mean female high observation (peak), when rounded to the nearest day, occurred on April 9 or 39.87 days into the male range (figure 2). The mean male high observation (peak), when rounded to the nearest day, occurred on April 13 or 43.82 days into the male range (figure 3 ).

A two-tailed t-test assuming unequal variances showed the mean male and female high observation frequency distributions differed significantly from each other; therefore, the null hypothesis was rejected $(\mathrm{t}=-6.97$; $\mathrm{P}<0.0001)$. The female high observation frequency distribution had a standard deviation of 8.96, a standard error of 0.41 , and a median of 39 days. The male high observation frequency distribution had a standard deviation of 9.74 , standard error of 0.39 , and a median of 44 days.

\section{A 95 percent confidence interval of the} difference in mean high observation dates between male and female sage-grouse was between 2.83 and 5.07 days. Thus, 95 percent of all 95 percent confidence intervals computed from this population in exactly the same way

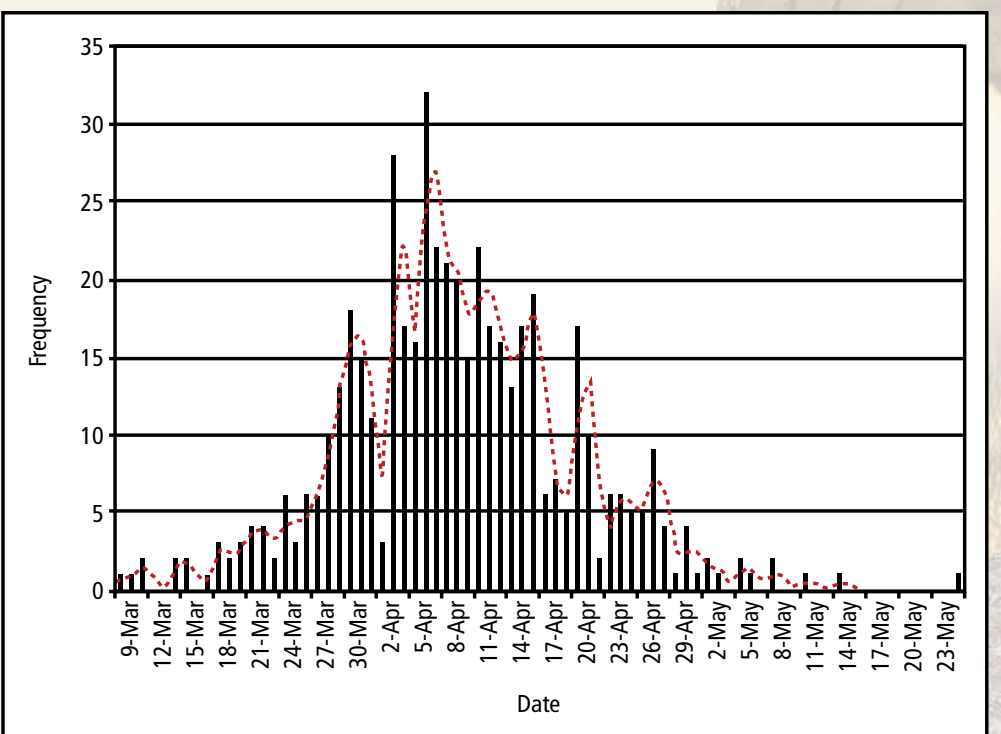

FIGURE 2. FREQUENCY AND MOVING AVERAGE (DASHED LINE) OF FEMALE HIGH OBSERVATIONS FOR DATA COLLECTED FROM 1958 THROUGH 2005 FOR EACH DATE WITHIN THE RANGE OF OBSERVATION.

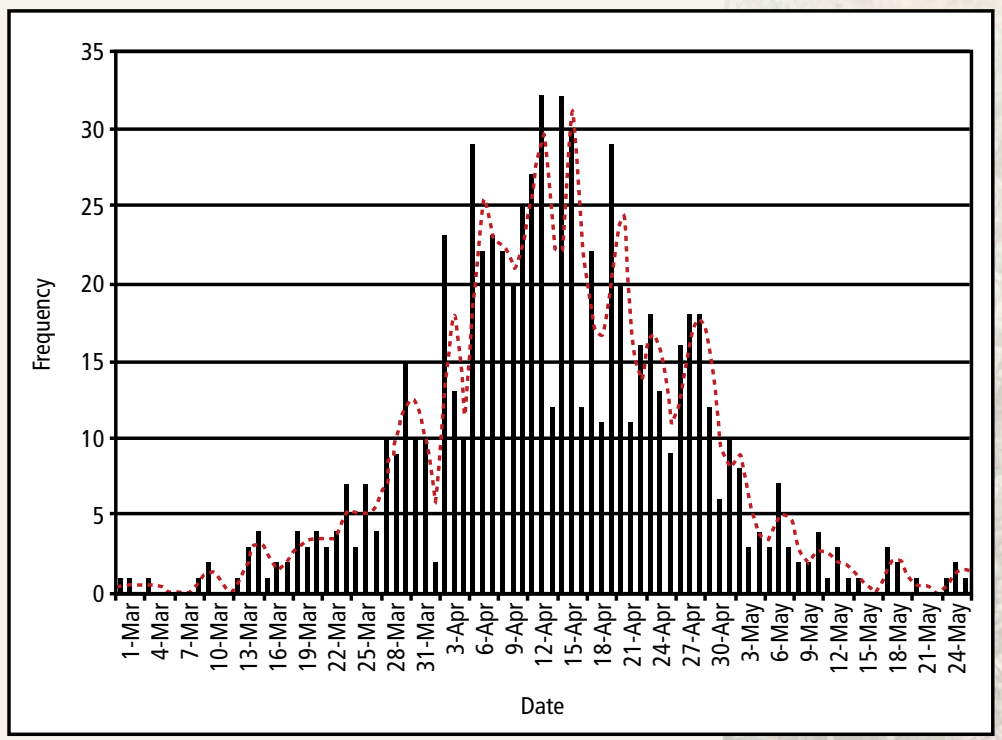

FIGURE 3. FREQUENCY AND MOVING AVERAGE (DASHED LINE) OF MALE HIGH OBSERVATIONS FOR DATA COLLECTED FROM 1958 THROUGH 2005 FOR EACH DATE WITHIN THE RANGE OF OBSERVATION. 
would contain the observed difference in means. There is sufficient evidence to conclude that the mean high observation of male (April 13) and female (April 9) sage-grouse differs significantly, and it appears that the mean dates of male high observations were later by 2.83 and 5.07 days on average than those of female high observations.

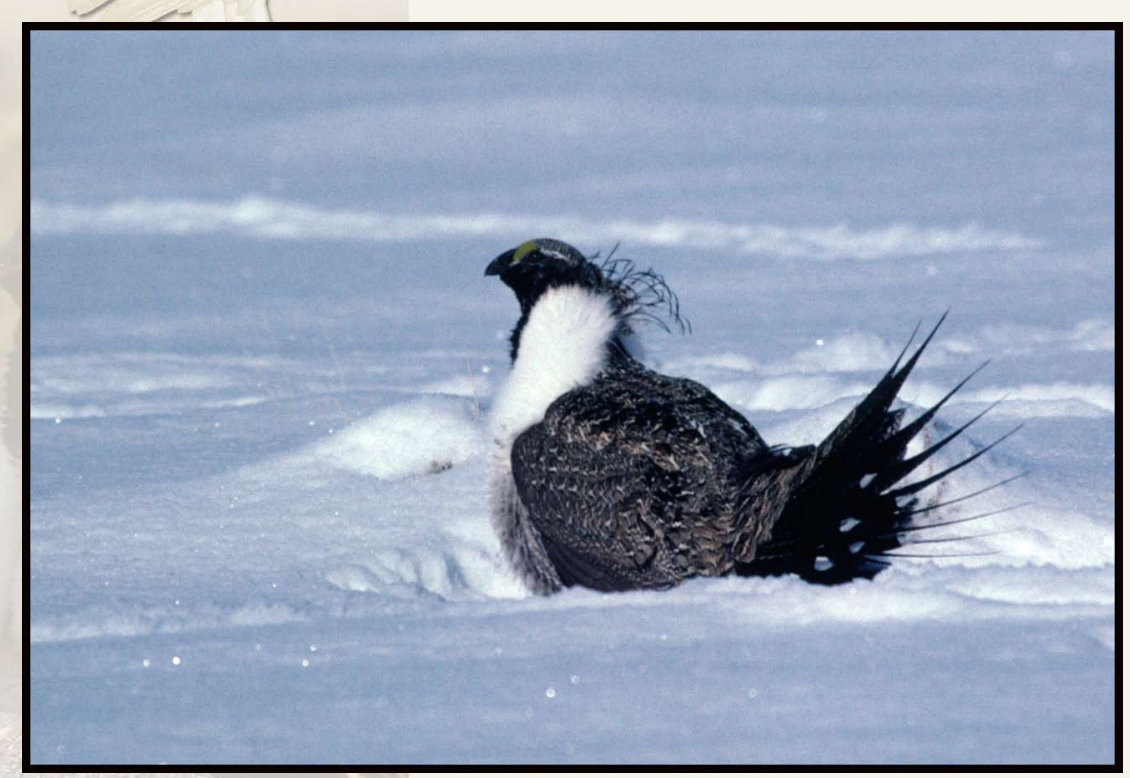

DAVE GOSWICK
Before data truncation, kurtosis values (which are a measure of "peakedness") were leptokurtic. A leptokurtic distribution has a more acute peak around the mean, or a higher probability than a normally distributed variable to have values near the mean. Females showed a greater peak, with positive values of 1.05 for females and 0.18 for males. After truncation, the frequency distribution showed negative kurtosis values, indicating a relatively less peaked distribution (male $=-0.60$ and female $=-0.40)$. The untruncated lek observation frequency distribution showed an average sampling effort into mid-April, or 51.34 days into the total sampling range (April 12), and the kurtosis value was 0.29. This mean value is between the male and female peaks and is less leptokurtic or platykurtic (a platykurtic distribution has a smaller peak around the mean). 


\section{DISCUSSION}

Although peak attendance may shift across years, this analysis of relatively long-term high observation lek attendance data suggests that on average there is a female attendance peak around April 9 and a male attendance peak around April 13, and that the male peak closely follows the female peak. This study assumes that the frequency distributions of high lek observations indicates the relative lek attendance season and peaks for males and females. The frequency distributions also show the relative occurrence of high observations throughout the lek attendance period. From March 1 through May 26, it may be possible to observe a peak lek attendance on a given lek for males and that for females this period may be from March 9 through May 25. This range of variability may be associated with weather pattern changes and disturbance from predators or human activity. The pronounced female peak is relatively similar to the male peak, suggesting the female attraction to leks for fertilization needs may correlate and be urgently associated with phenological development of suitable nesting conditions. The female peak may also be related to female attraction to leks by male display efforts encouraged by female attendance and male competitive interactions. There may be smaller embedded activity peaks; however, these data were only analyzed for one peak representing each frequency distribution.

The female peak attendance suggests that hens may begin nest initiation activity around April 12 (3 days after mating) and begin incubating nests around April 21 (9 days to complete an average clutch). This is about a week earlier than the higher elevation leks in the Patterson (1952) study. Peak separation was less than 1 week (2.83 to 5.07 days) and not 3 to 5 weeks as reported elsewhere (Eng 1963; Jenni and Hartzler 1978; Emmons and Braun 1984; Connelly et al. 2004). Peak lek attendance for the northern Bighorn Basin appears to be relatively early, and the peaks are more proximal than those that have been reported for Wyoming and other Western States (Patterson 1952; Connelly et al. 2004).

These results suggest that the male peak follows the female peak closely and slowly tapers off as the season advances. If diminished intrasexual competition contributes substantially to the male peak, then there should be a larger male and female peak separation (Mercedes 1983; Beehler and Foster 1988; Trail 1990). The results of the present study showed a significant separation of less than a week; this suggests male intrasexual competition and female sexual selection may be mechanisms keeping the two peaks close to each other yet separate (Cox and Le Boeuf 1977; Mercedes 1983; Beehler and Foster 1988; Trail 1990; Hartzler and Jenni 1998).

A study exploring the period in which most copulation occurs and how closely it is associated with female peak attendance and a study investigating peak fledging and brood-rearing activity would be very helpful to managers who currently must extrapolate female nest initiation, fledging, and brood-rearing periods (Eng 1963; Schroeder 1997). Since there are currently small data sets on these periods, applying life history observations by Patterson (1952) provides nonlocal data for local nesting, fledging, and brood-rearing activity estimates, which are not ideal. 
More current and local information would improve the accuracy of these estimates. The

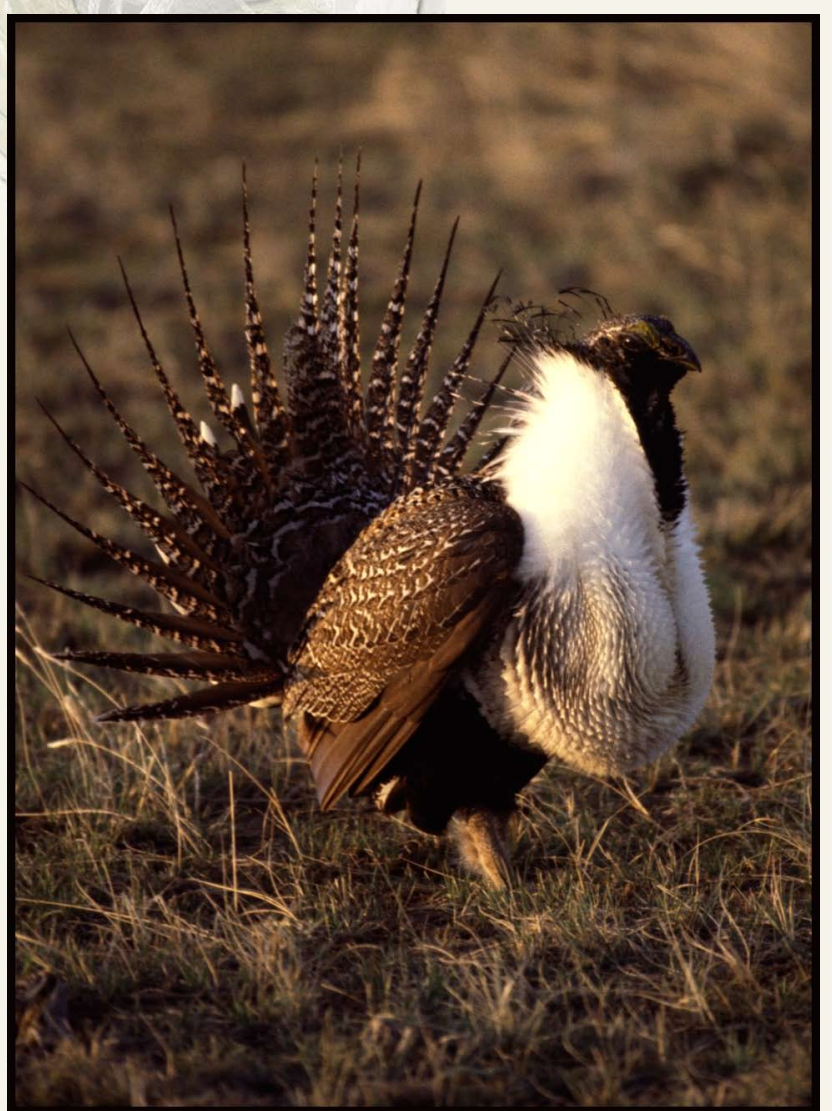

present study indicates when females are most frequently attending leks, presumably for mating. If April 9 is indeed the local female attendance peak, much of the broodrearing activity may actually be earlier than June as reported by Patterson (1952) and may occur or begin around May 16 through May 18 (25 to 27 days for incubation) in the northern Bighorn Basin. These types of estimates could be used until more direct data are collected from DAVE GOSWICK nesting fledging, and brood-rearing studies.

Currently, lek counts are conducted in the northern Bighorn Basin, within a monitoring period guideline of early March through early May. This period does not incorporate all lek attendance and may be excluding attendance during the early and later periods (Walsh et al. 2004). If females attend leks to mate, early and late attendance by females suggest that nesting activity could begin anytime from March 9 through May 25. Early female attendance may be a result of natural annual nest initiation variability and adult females nesting earlier than yearlings (Schroeder 1997). Late attendance may be due to renesting attempts after a failed nest (Connelly et al. 1993). Milder climate associated with lower elevation in the northern Bighorn Basin may be a possible explanation for the earlier attendance peaks and life history activities.

Adult and juvenile survival and reproduction rates have been identified as limiting factors for sage-grouse populations (Johnson and
Braun 1999). Avoiding local sensitive life history periods may attenuate the effects on sage-grouse from harmful disturbances (Crawford et al. 2004). Using peak attendance information along with life history information could help determine local sensitive periods when sage-grouse are vulnerable to disturbances affecting survival and reproduction.

When specific life history details are considered and efforts are made to work outside of sensitive periods, disturbances such as habitat manipulations may be tolerated better by sage-grouse (Connelly et al. 2000; Lyon and Anderson 2003). Evidence from designed experiments with sage-grouse has shown that adult and juvenile survival demographic factors may respond positively to habitat manipulations when designed appropriately (Johnson and Braun 1999). Activities such as mowing and prescribed burning that achieve low sagebrush reduction levels and are implemented outside of the lek attendance and nesting season may benefit adult and juvenile survival by providing a more diverse habitat condition (Johnson and Braun 1999; Aldridge and Boyce 2007).

Similar considerations should be applied for habitat disturbances that are distant from leks, which also appears to be important for sage-grouse. Holloran and Anderson (2005) showed nest distribution is spatially related to lek locations. They also showed greater nest success in lower densities, suggesting that the use of available sage-grouse habitat distant from leks may reduce mechanisms of enhanced detection by predators around leks (Holloran and Anderson 2005). Also, evidence that habitat regulations for sagegrouse appear to be applied homogeneously throughout a region further illustrates the need for also considering habitat impacts during sensitive life history periods on habitat distant from leks (LaMontagne et al. 2002). These studies suggest the BLM's current 0.4-km (1/4-mi) no surface occupancy buffer and $3.2-\mathrm{km}(2-\mathrm{mi})$ seasonal surface disturbing stipulations may be insufficient to maintain activity at a lek and contain a lesser percentage of nests (LaMontagne et al. 2002; Holloran and Anderson 2005). 
Lek attendance and nesting periods are vulnerable times for sage-grouse and they may be sensitive to surface-disturbing activities, which take many forms (Lyon and Anderson 2003; Crawford et al. 2004). Care should be taken when disturbing sage-grouse habitat regardless of the exact distance from a lek. Vegetation treatments and new development should incorporate the appropriate treatment season and spatial placement to minimize nest destruction and lek attendance disturbance and to maintain quality habitat for the longterm. Results from this study, along with the growing body of sage-grouse life history data, can be used to make better informed decisions on activities overlapping the lek attendance and nesting seasons.

In this analysis, past data were pooled for a large sample size that includes many leks over many years, increasing the precision of the analysis. An even greater sample size may show smaller peaks currently indistinguishable from these data. As this data set incorporates longer periods of time, smaller increments of time should be compared to analyze whether or not peak lek attendance periods are shifting, perhaps from climate change.

Beginning in 1980, sampling efforts were intensified and therefore may better represent this period's population. Observations from before 1980 were still included in the analysis to help reduce effects of variability among years. Such variability may be explained by the natural fluctuations in lek attendance activity framed by various constraining factors: climate, anthropogenic disturbance, phenology, physiology, and behavior. Females attempting to nest early may lose their eggs to cold weather or depredation, may return to the lek to mate, and then may reinitiate nesting
(Jenni and Hartzler 1978). Males may also be less fertile later in the season, limiting the possibility of renesting and decreasing the potential for late broods (Eng 1963).

Potential sources of bias and error exist common to historical data. The pooled data were collected from leks that occur within a wide range of environmental variables.

Unfavorable weather may disrupt scheduled visits to observe certain leks. High observations were sometimes determined by single or many lek surveys for the season or by using multiple observers, producing differential visual detection rates. Male and female detection rates are different, where observers may be more likely to inaccurately detect females. Leks may have been selected for known historically high observations. The high observation date is based on the Gregorian calendar and the associated error involved with this calendar system, specifically leap year corrections.

All of these variables certainly have an effect on the precision and accuracy of the results; however, sources of error such as these do not eliminate the usefulness of these data, and interpretation should acknowledge all sources of bias (Walsh et al. 2004; Bart 2005). Results still show a significant difference between peaks of high male and female sage-grouse lek attendance and help describe their temporal separation during the lek attendance season. In the future, efforts to improve systematic random sampling of sage-grouse lek attendance throughout the season may produce more precise and accurate results that further limit bias. The amount of lek attendance data continues to increase and taking advantage of these growing data sets by using them to determine peak attendance periods is important for sage-grouse conservation (Schroeder 1997). 


\section{LITERATURE CITED}

Aldridge, C. and M.S. Boyce. 2007. Linking occurrence and fitness to persistence: habitat-based approach for endangered greater sage-grouse. Ecological Applications 17:508-526.

Bart, J. 2005. Monitoring the abundance of bird populations. The Auk 122:15-25.

Beehler, B.M. and M.S. Foster. 1988.

Hotshots, hotspots, and female preference in the organization of lek mating systems. The American Naturalist 131:203-219.

Braun, C.E. and T.D.I. Beck. 1996. Effects of research on sage grouse management. Transactions of the North American Wildlife and Natural Resources Conference 61:429-436.

Braun, C.E. and K.H. Johnson. 1999.

Viability and conservation of an exploited sage grouse population. Conservation Biology 13:77-84.

Christiansen, T. 2005. 2005 greater sage-grouse job completion report. Wyoming Game and Fish Department. 319 pp.

Connelly, J.W. and E.E. Braun. 1997. Longterm changes in sage-grouse (Centrocercus urophasianus) populations in Western North America. Wildlife Biology 3:229-234.

Connelly, J.W., R.A. Fischer, A.D. Apa, K.P. Reese, and W.L. Wakkinen. 1993. Renesting by sage grouse in southeastern Idaho. The Condor 95:1041-1043.

Connelly, J.W., S.T. Knick, M.A. Schroeder, and S.J. Stiver. 2004. Conservation assessment of greater sage-grouse and sagebrush habitats. Western Association of Fish and Wildlife Agencies. Unpublished report. Cheyenne, Wyoming.
Connelly, J.W., K.P. Reese, and M.A.

Schroeder. 2003. Monitoring of greater

sage-grouse habitats

and populations.

Station Bulletin 80 .

College of Natural

Resources Experiment Station, University of Idaho, Moscow.

Connelly, J.W., M.A. Schroeder, A.R. Sands, and C.E. Braun. 2000. Guidelines to manage sage grouse populations and their habitats. Wildlife Society Bulletin 28:967-985.

Cox, C.R. and B.J. Le Boeuf. 1977. Female incitation of male competition: a mechanism in sexual selection. The American Naturalist 111:317-335.

Crawford, J.A., R.A. Olson, N.E. West, J.C. Mosley, M.A.

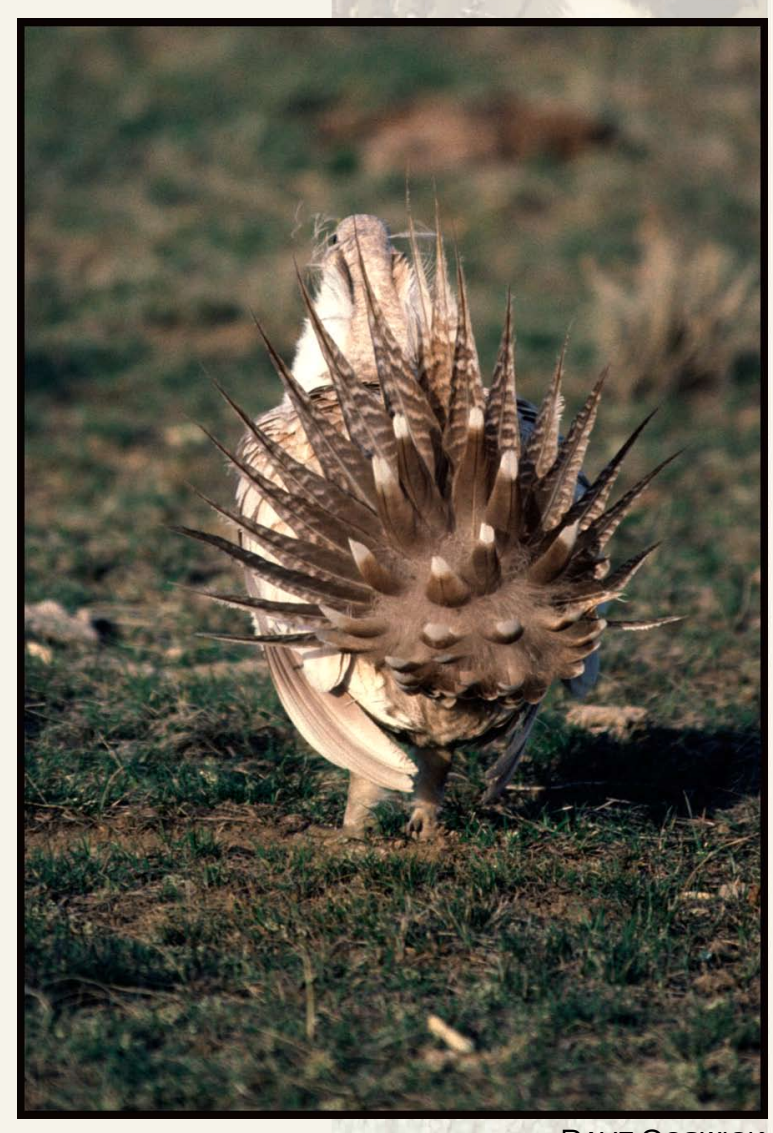

Schroeder, T.D. Whitson, R.F. Miller, M.A. DAVE GosWICK Gregg, and C.S. Boyd. 2004. Ecology and management of sage-grouse and sage-grouse habitat. Journal of Range Management 57:2-19.

Easterly, T. 2000. Sage grouse annual report and summary of data for the Cody Region, 1956-1999. Unpublished report. Wyoming Game and Fish Department. 29 pp. 
Emmons, S. R. and C.E. Braun. 1984. Lek attendance of male sage grouse. Journal of Wildlife Management 48:1023-1028.

Eng, R.L. 1963. Observations of the breeding biology of male sage grouse. Journal of Wildlife Management 27:841-846.

Hartzler, J.E. and D.A. Jenni. 1998. Mate choice by female sage grouse. In A.T. Bergerud and M.W. Gratson, editors. Adaptive strategies and population ecology of northern grouse. University of Minnesota Press, Minneapolis. pp. 240-269.

Holloran, M.J. and S.H. Anderson. 2005. Spatial distribution of greater sage-grouse nests in relatively contiguous sagebrush habitats. The Condor 107:742-752.

Holloran, M.J., B.J. Heath, A.G. Lyon, S.J. Slater, J.L. Kuipers, and S.H. Anderson. 2005. Greater sage-grouse nesting habitat selection and success in Wyoming. Journal of Wildlife Management 69:638-649.

Jenni, D.A. and J.E. Hartzler. 1978.

Attendance at a sage grouse lek: implications for spring censuses. Journal of Wildlife Management 42:46-52.

Johnson, K.H. and C.E. Braun. 1999. Viability and conservation of an exploited sage grouse population. Conservation Biology 13:77-84.

LaMontagne, J.M., R.L. Irvine, and E.E. Crone. 2002. Spatial patterns of population regulation in sage grouse (Centrocercus spp.) population viability analysis. Journal of Animal Ecology 71:672-682.

Lowry, R. 2007. Vassarstats: web site for statistical computation. http://faculty.vassar. edu/lowry/VassarStats.html (accessed Feb. 25, 2007).

Lyon, A.G. and S.H. Anderson. 2003. Potential gas development impacts on sage grouse nest initiation and movement. Wildlife Society Bulletin 31:486-491.
Mercedes, S.F. 1983. Disruption, dispersion, and dominance in lek-breeding birds. The American Naturalist 122:53-72.

Patterson, R.L. 1952. The sage grouse in Wyoming. The Wyoming Game and Fish Commission and Sage Books. Denver, Colorado.

Schroeder, M.A. 1997. Unusually high reproductive effort by sage grouse in a fragmented habitat in north-central Washington. Condor 99:933-941. Schroeder, M.A., C.L. Aldridge, A.D. Apa, J.R. Bohne, C.E. Braun, S.D. Bunnell, J.W. Connelly, P.A. Deibert, S.C. Gardner, M.A. Hilliard, G.D. Kobriger, S.M. McAdam, C.W. McCarthy, J.J. McCarthy, D.L. Mitchell, E.V. Rickerson, and S.J. Stiver. 2004. Distribution of sage-grouse in North America. Condor 106:363-376.

Stiver, S.J., A.D. Apa, J.R. Bohne, S.D. Bunnell, P.A. Deibert, S.C. Gardner, M.A. Hilliard, C.W. McCarthy, and M.A. Schroeder. 2006. Greater sage-grouse comprehensive conservation strategy. Western Association of Fish and Wildlife Agencies. Unpublished report. Cheyenne, Wyoming.

Trail, P.W. 1990. Why should lek-breeders be monomorphic? Evolution 44:1837-1852.

Walsh, D.P., G.C. White, T.E. Remington, and D.C. Bowden. 2004. Evaluation of the lek-count index for greater sage-grouse. Wildlife Society Bulletin 32:56-68.

Young, J.R. 1994. The influence of sexual selection on phenotypic and genetic divergence among sage grouse populations. Dissertation. Purdue University, West Lafayette, Indiana. 


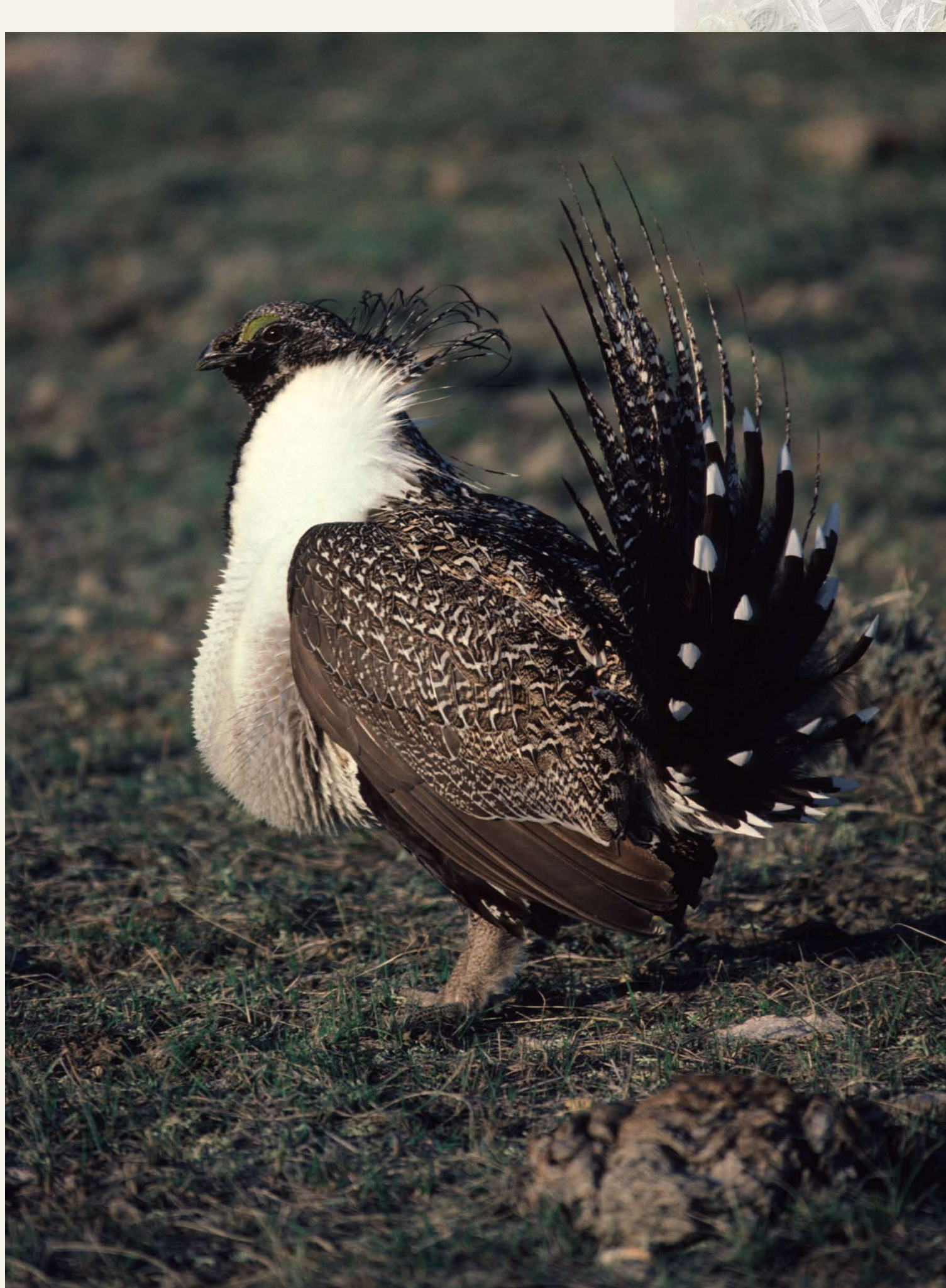

The mention of company names, trade names, or commercial products does not constitute endorsement or recommendation for use by the Federal Government. 